\title{
Author Correction: Impact of
} ezetimibe on plasma lipoprotein(a) concentrations as monotherapy or in combination with statins: a systematic review and metaanalysis of randomized controlled trials

\section{Amirhossein Sahebkar, Luis E. Simental-Mendía, Matteo Pirro, Maciej Banach, Gerald F. Watts, Cesare Sirtori, Khalid Al-Rasadi \& Stephen L. Atkin (1)}

Correction to: Scientific Reports https://doi.org/10.1038/s41598-018-36204-7, published online 14 December 2018

The original version of this Article contained a typographical error in the spelling of the author Cesare Sirtori, which was incorrectly given as Cesare Sirotri.

Additionally, the original version of this Article omitted an affiliation for Amirhossein Sahebkar. The correct affiliations for Amirhossein Sahebkar are listed below:

Halal Research Center of IRI, FDA, Tehran, Iran.

Biotechnology Research Center, Pharmaceutical Technology Institute, Mashhad University of Medical Sciences, Mashhad, Iran.

Neurogenic Inflammation Research Center, Mashhad University of Medical Sciences, Mashhad, Iran.

School of Pharmacy, Mashhad University of Medical Sciences, Mashhad, Iran.

This has now been corrected in the HTML and PDF versions of this Article.

\begin{abstract}
(c) (i) Open Access This article is licensed under a Creative Commons Attribution 4.0 International cc. License, which permits use, sharing, adaptation, distribution and reproduction in any medium or format, as long as you give appropriate credit to the original author(s) and the source, provide a link to the Creative Commons license, and indicate if changes were made. The images or other third party material in this article are included in the article's Creative Commons license, unless indicated otherwise in a credit line to the material. If material is not included in the article's Creative Commons license and your intended use is not permitted by statutory regulation or exceeds the permitted use, you will need to obtain permission directly from the copyright holder. To view a copy of this license, visit http://creativecommons.org/licenses/by/4.0/.
\end{abstract}

(C) The Author(s) 2020 